\title{
APPLICATION OF LOGISTIC REGRESSION IN COUNTERFACTUAL IMPACT EVALUATION OF GRADUATE PRACTICE MEASURE IN SLOVAKIA
}

\author{
LUCIA SVABOVA \\ University of Zilina, The Faculty of Operation and Economics of Transport and Communications, \\ Department of Economics, Univerzitna 8215/1, 01026 Zilina, Slovakia \\ email: lucia.svabova@fpedas.uniza.sk
}

\section{MAREK DURICA}

University of Zilina, The Faculty of Operation and Economics of Transport and Communications, Department of Quantitative Methods and Economic Informatics, Univerzitna 8215/1, 01026 Zilina email: marek.durica@fpedas.uniza.sk

\begin{abstract}
In the paper we discuss the results of Counterfactual impact evaluation of Graduate practice that is one of Active labour market policy (ALMP) interventions in Slovakia for unemployed jobseekers. Counterfactual impact evaluation is usually made using various multivariate statistical methods; one of the most used methods is Propensity score matching. Propensity score for every individual jobseeker means the probability of taking a part of an ALMP intervention and can be obtained using logistic regression model. Counterfactual evaluation is based on comparison of placeability and sustainability of treated and non-treated jobseekers on open labour market and is very important for valuation of impact of intervention not only on individual jobseekers and their employability but also for valuation of whole intervention and its economic impact.
\end{abstract}

Key words: Logistic regression, Propensity score matching, Counterfactual impact evaluation, Active labour market policy, Intervention

JEL Codes: J08, J68

DOI: 10.15611/amse.2017.20.39

\section{Introduction}

Public programs are designed to reach certain goals and beneficiaries. Programs might appear potentially promising before implementation yet fail to generate expected impacts or benefits. The obvious need for impact evaluation is to help policy makers to decide whether programs are generating intended effects; to promote accountability in the allocation of resources across public programs; and to fill gaps in understanding what works, what does not, and how measured changes in well-being are attributable to a particular project or policy intervention. (Khandker et al., 2010)

The main challenge of an impact evaluation is to determine what would have happened to the beneficiaries if the intervention had not existed. (Holmlund, 2001) That is, to determine the income of beneficiaries in case of absence of the intervention. A beneficiary's outcome in the absence of the intervention would be its counterfactual. A program or policy intervention seeks to alter changes in the well-being of beneficiaries. Ex post, outcomes of this intervention on intended beneficiaries, such as employment or expenditure, are quantified. 
Then the question is, whether this change does relate directly to the intervention and whether this intervention has caused expenditure or employment to grow. At best it is possible to evaluate whether the objective of the intervention was met. But the result after the intervention cannot be attributed to the program itself. (Khandker et al., 2010)

Active Labour Market Policies (ALMP) are a favored measures used by policymakers in the European Union as tools for regional revitalization. (Bondonio and Greenbaum, 2014) The main European instrument to support employment and social inclusion is The European Social Fund (ESF). In the programming period 2007 - 2013, the ESF spent nearly $€ 76,5$ billion on ALMP implemented through operational programs in the 27 Member States of EU. Evaluations of interventions of ALMP aim to improve the quality, effectiveness, and consistency of the assistance from the Funds, strategy and implementation of the operational programs. (European Commision, 2012)

In years 2015 - 2016 after the end of programming period 2007 - 2013, Pilot Projects to carry out ESF related Counterfactual Impact Evaluations were realized at the request of European Commission. Under this project, the evaluations have been made in several countries of European Union: Slovakia, Lithuania, Portugal, Spain, Poland, etc.

\subsection{Evaluation of interventions in Slovakia}

Increasing the rate of employment and decreasing unemployment were, and still remaining, some of the general objectives of the Slovak government. This goal was applied also in the Operational Programme Employment and Social Inclusion for the programming period 2007 2013, due to the situation in the country regarding the critically high rate of the unemployed economically active population. In this respect, specific interventions of ALMP were proposed to be carried out with the aim of assisting in the improvement of the population's employability.

Although the funding sources for these interventions come mostly from structures of EU, the EU therefore calls for rigorous analyses, especially counterfactual evaluations, of the effectiveness of these measures. This evaluation was in Slovakia realized in years $2015-$ 2016 at the request of the European Commission, the Ministry of Labour, Social Affairs and Family of the Slovak Republic (MOLSAF) after the end of programming period 2007-2013. The evaluation was made using as large a sample as was possible: 130 thousand participants and non-participants according to available individual data from Central Office of Labour and Social Affairs (COLSaF) and Social Insurance Agency (SIA). The main aim was to estimate the net effect of selected ALMP interventions. In other words, to find an answer to the fundamental counter-factual question: what would have happened if the intervention had not been provided or promoted? Quite simply, it is possible to say that the counterfactual methods subtract the individual performance of participants and non-participants in the impact period 2 years after the intervention had finished.

\section{Evaluation methods}

In the evaluation of the effects of selected ALMP intervention, various approaches should be used. One of the easiest methods is Post-only Non-equivalent Comparison Design. It is based on a comparison of post-intervention data, i.e. the results of supported and unsupported individuals on the labour market in their individual impact period. The main problem with this method is that the intervention group and control group can be monitored at different times. Nevertheless, the main advantage of this approach is its simplicity of use and less data demands. (Borik et al., 2015) 
The second method that can be used in the evaluation of selected ALMP interventions is Exact Matching. (Potluka and Bruha, 2011) This method is similar to the previous one, but the difference is in exact conformity, which is applied in the process of matching individuals from the supported and unsupported groups according to the individual characteristics. (Szitasiova, 2015)

One of the mostly used methods for evaluations of ALMP interventions are surely a counterfactual method called Propensity score matching (PSM). (Lindley et al., 2015)

In this paper we focus on this method, so we will describe it in more detail.

\subsection{Propensity score matching}

The propensity score is the probability that an individual will be in treatment group given his or her observed covariates. (Asian Development Bank, 2014) PSM constructs a statistical comparison group based on a model of the probability of participating in the treatment, using observed characteristics. (Potluka et al., 2012) Participants are then matched on the basis of their propensity score to non-participants. The average treatment effect of the program is then calculated as the mean difference in outcomes across these two groups. (Khandker et al., 2010)

Different approaches are used to match participants and non-participants on the basis of the propensity score:

- Nearest-neighbor $(\mathrm{NN})$ matching, where each treatment unit is matched to the comparison unit with the closest propensity score. It is possible to choose the number of nearest neighbors, usually 5 is used. Matching can be done with or without replacement. Matching with replacement means that the same nonparticipant can be used as a match for different participants. (Khandker et al., 2010)

- Caliper or radius matching is similar to the NN matching, but to solve the problem with possible poor matches a "tolerance" on the maximum propensity score distance (caliper) is used. This procedure therefore involves matching with replacement, only among propensity scores within a certain range.

- Stratification or interval matching partitions the common support into different strata (or intervals) and calculates the program's impact within each interval.

- Kernel and local linear matching use a weighted average of all nonparticipants to construct the counterfactual match for each participant. (Rodrigues and Benus, 2006)

- Difference-in-difference matching is constructed with data on participant and control observations before and after program intervention.

A number of steps, therefore, can be used to match participants to nonparticipants. Comparing results across different matching methods can reveal whether the estimated program effect is robust. (Khandker et al., 2010)

In the evaluation realized in Slovakia were used two methods: nearest-neighbor matching and caliper matching. Then, the non-participants assume the impact period from matched participants. Matching was used without replacement, so one non-participant can be used as a match to participants only once. (Durica, 2016)

In this paper we present the application of logistic regression in counterfactual impact evaluation of Graduate practice measure in Slovakia as a tool for one of the most used counterfactual methods, propensity score matching. Then we will show the evaluation results using caliper matching of propensity score. (Stankovicova and Vojtkova, 2007; Kral et al., 2009). 


\section{Data}

The evaluation realized in Slovakia at the request of the European Commission was focused on the period ended in the year 2012. There were two selected ALMP intervention that have been evaluated: Graduate practice and Self-employment. The period has been divided into several reference periods because of revisions of the Act during these years. In this paper we will present the evaluation of Graduate practice in the last reference period, i.e. from 1.7.2011 to 30.4.2012. We will focus on the counterfactual evaluation using Propensity score matching with caliper matching technique.

\subsection{Graduate practice}

Graduate practice is one of the most frequently used interventions within ALMP measures. It is focused on young unemployed jobseekers to improve their weak ability to be placed on the labour market due to their lack of skills. (Pirog, 2015)

Graduate practice is the intervention stated in $\S 51$ of Act no. 5/2004 Coll. The primary purpose of graduate practice is to create the conditions for obtaining the relevant professional skills and practical experience which will be valuable and attractive for potential employer on the open labour market to ensure a higher rate of employability for graduates. Every jobseeker included in the treated or non-treated samples has 24 months of impact period starting from the individual date of the end of intervention. (Borik et al., 2015)

\subsection{Description of the data}

The intention of the evaluators was to use all relevant and available data sources about all treated and eligible controls. The most important database was the database of treated and non-treated jobseekers maintained by COLSaF and supported by regional Public Employment Services offices. In total, we obtained 2886510 records from COLSaF. In the dataset, one jobseeker has multiple records about different registration periods. These records contains individual characteristics of the jobseekers, such as: gender, age, marital status, permanent residence, level of education, type of school, driving licenses, disadvantages, period of registration before the evaluation, date of entry and date of departure from the database of jobseekers, etc. These data are used as treatment variables in the process of creation of logistic regression model to predict the probability of individual participation in the intervention.

The other most important data source was the database of the Slovak Insurance Agency. These data are mostly output data in the context of an intervention log. Mostly the data monitored dependent variables based on employability: registrations as employee, voluntarily insured person, partially-employed registrations, self-employed registrations and month income represented by assessment base. These data are treatment characteristics and are used to evaluate the effects of the intervention: placeability and sustainability of jobseekers on the open labour market and their monthly wage.

Moreover, to avoid the self-selection effect problem, the context data about the living environment of the jobseekers were used: population of the municipality, change of the population in the last 15 years in the municipality, real distance from permanent residence to the local Public Employment Services office. These control variables are used in the logistic regression as the instrumental variables to decrease the selection bias. (Paz, 2014)

In the reference period of evaluation, presented in this paper, we had the following sample sizes: the group of treated jobseeker consisted of 3599 individuals and control group of nontreated jobseekers consisted of 4486 individuals. So in total we had 8085 jobseekers in the dataset. 


\section{Modeling the probability of being treated and evaluation results}

The probability of taking a part in the Graduate practice intervention could be modeled by using the logistic regression, where the dependent variable is binary: value 1 for jobseeker intervened by Graduate practice, 0 for jobseeker that is control unit, i.e. was not treated by this intervention. The probability of being treated is estimated by logistic regression with all above mentioned variables represented personal characteristics and characteristics of living environment of every jobseeker as explanatory variables.

Original number of variables in the logistic regression procedure was 26, where 9 of them were categorical variables. Categories are in the following table.

Table 1: Categories of categorical variables

\begin{tabular}{|c|c|}
\hline Categorical variable & Categories \\
\hline \multirow[b]{2}{*}{ Gender } & Male \\
\hline & Female \\
\hline \multirow{3}{*}{ Marital status } & Single \\
\hline & married and registered partners \\
\hline & Divorced \\
\hline \multirow{5}{*}{ School } & primary schol \\
\hline & secondary vocational school \\
\hline & vocational school \\
\hline & comprehensive school \\
\hline & Colledge \\
\hline \multirow[b]{2}{*}{ Disadvantages } & no disadvantage \\
\hline & some disadvantage \\
\hline \multirow{3}{*}{ Unemployed before evaluation } & less than 3 years \\
\hline & more than 3 years \\
\hline & no evidence \\
\hline \multirow[b]{2}{*}{ Driving licence_cars and motocycles } & Yes \\
\hline & No \\
\hline \multirow{2}{*}{ Driving licence_small trucks } & Yes \\
\hline & No \\
\hline \multirow{2}{*}{ Driving licence_buses } & Yes \\
\hline & No \\
\hline \multirow{2}{*}{ Driving licence_vans } & Yes \\
\hline & No \\
\hline
\end{tabular}

Source: the author's work

A variable disadvantage was used as binary variable. The most frequent disadvantage was "graduate", all other disadvantages had almost zero frequencies, so we put all disadvantages together. Since we use a detailed classification of education level into 10 categories, we considered this ordinal variable as a numeric variable and thus we also used it in logistic regression. This gives us a lot of flexibility in our choice of analysis and preserves the information in the ordering. (Field, 2014)

In logistic regression procedure we used the backward conditional stepwise method, with the condition of entry probability 0.01 and removal probability 0.05 . Using the backward conditional method we get the final best logistic regression for modelling the probability (or 
odds) of participating in the program with the given independent variables. The coefficients of independent variables used in the final logistic regression model are in the Table 2.

The values of coefficient $\operatorname{Exp}(B)$ we can interpret in the following way: if the value of for example Age increases by 1 year, that means the participant or non-participant will be 1 year older, and all other variables stay the same, then the odds that the individual will belong to the treated group will be 0.420 times higher. The coefficient of Age is smaller than 1, therefore increasing Age changes the odds that the unit is treated 0.420 times (e.g. decreases the odds). For variable education level the influence is stronger. With a higher education level of 1 degree the odds of being treated will increase 4.357 times, if the values of all other variables stay the same. Similarly for variables unemployed in months, disadvantages and total period of all registrations. According to the value of coefficient for gender, we can say that the odds of being treated are for women about $75 \%$ higher than for men.

Table 2: Logistic regression model in Graduate practice evaluation

\begin{tabular}{|c|c|c|c|c|c|c|}
\hline \multicolumn{7}{|c|}{ Logistic regression model variables, reference period 4} \\
\hline Variable & B & S.E. & Wald & df & Sig. & $\operatorname{Exp}(B)$ \\
\hline Gender & 0,561 & 0,046 & 150,048 & 1 & 0,000 & 1,752 \\
\hline Age & $-0,868$ & 0,016 & 3085,285 & 1 & 0,000 & 0,420 \\
\hline Marital status_category1 & 1,297 & 0,568 & 5,221 & 1 & 0,022 & 3,659 \\
\hline Marital status_category2 & $-0,233$ & 0,102 & 5,271 & 1 & 0,022 & 0,792 \\
\hline Education level & 1,472 & 0,059 & 612,059 & 1 & 0,000 & 4,357 \\
\hline School_category1 & 1,568 & 0,449 & 12,218 & 1 & 0,000 & 4,797 \\
\hline School_category2 & 1,653 & 0,244 & 45,914 & 1 & 0,000 & 5,225 \\
\hline School_category3 & 1,665 & 0,256 & 42,181 & 1 & 0,000 & 5,287 \\
\hline School_category4 & 0,733 & 0,198 & 13,752 & 1 & 0,000 & 2,082 \\
\hline Disadvantages & 0,450 & 0,031 & 212,018 & 1 & 0,000 & 1,568 \\
\hline Unemployed in months & 0,197 & 0,004 & 2266,850 & 1 & 0,000 & 1,218 \\
\hline Total period of all registrations & 0,010 & 0,002 & 18,166 & 1 & 0,000 & 1,010 \\
\hline Unemployed before evaluation_category1 & 2,038 & 0,192 & 112,106 & 1 & 0,000 & 7,673 \\
\hline Unemployed before evaluation_category2 & 2,140 & 0,419 & 26,075 & 1 & 0,000 & 8,497 \\
\hline Driving licence_cars and motocycles & $-0,103$ & 0,050 & 4,202 & 1 & 0,040 & 0,902 \\
\hline Driving licence_small trucks & $-0,443$ & 0,163 & 7,385 & 1 & 0,007 & 0,642 \\
\hline Average gross wage in region of permanent residence & $-0,001$ & 0,000 & 19,413 & 1 & 0,000 & 0,999 \\
\hline Proportion of women in district of permanent residence & $-0,074$ & 0,035 & 4,375 & 1 & 0,036 & 0,929 \\
\hline Surface of district of permanent residence & 0,000 & 0,000 & 12,940 & 1 & 0,000 & 1,000 \\
\hline Number of cities in district of permanent residence & $-0,076$ & 0,028 & 7,563 & 1 & 0,006 & 0,927 \\
\hline Population of municipality_2011 & 0,000 & 0,000 & 15,783 & 1 & 0,000 & 1,000 \\
\hline Distance from PES Office & $-0,010$ & 0,003 & 12,950 & 1 & 0,000 & 0,990 \\
\hline Constant & 11,405 & 1,810 & 39,723 & 1 & 0,000 & 89745,687 \\
\hline
\end{tabular}

Source: the author's work

For categorical variables such as school, the value of coefficient $\operatorname{Exp}(\mathrm{B})$ can be interpreted for every category compared to the reference category as follows: for example, the units with primary school (category 1) have 4.797 times higher odds of belonging to the group of treated individuals than the units with college (reference category). Similarly for the other categories of school in comparison with the reference category college, all of them have higher odds to be intervened than college, of course ceteris paribus. 
Another categorical variable, unemployed before evaluation, for example the jobseeker registered less than 3 years (category 1) has 8.497 times higher odds of belonging to the group of treated units than the jobseeker without any evidence before the evaluation time (reference category).

Similarly for marital status. As can be supposed, single individual (category 1) have 3.659 times higher odds of taking a part in Graduate practice intervention than divorced (reference category). On the contrary, married individual (category 2) have 0.792 times lower odds of taking a part in Graduate practice than divorced individual.

Interesting results are also for some categories of driving license. If the jobseeker have a license for cars and motorcycles, the odds that will be in the treated group of Graduate practice is 0.920 times lower than for the jobseeker without this driving license. Similarly it is for small trucks driving license where the multiple of the odds is even lower: 0.642.

The other variables in the logistic regression model in Table 2 were used as the instrumental variables and serve on elimination of the selection bias problem.

This model has quite good classification ability. The percentage of correctly classified cases is more than $90 \%$ (according to SPSS output classification table); the Nagelkerke Rsquare is more than 0.80 . The coefficient of all variables is significant with a significance level of 0.05 in the Wald test for logistic regression coefficients.

\subsection{Graduate practice evaluation results}

Above mentioned logistic model was used in the counterfactual evaluation in Propensity score matching method with exact matching technique. This approach is composed of:

- creation of a logistics model using personal characteristics of jobseekers and their living environment,

- using the predicted values from the logistic regression for estimation of the probability of being treated (propensity score) by Graduate practice for every individual in the samples of treated and controls,

- matching only those individuals that have the same propensity score,

- non-treated jobseeker adopted individual impact period of the treated jobseeker who was matched with the non-treated,

- estimation of the net effect of Graduate practice as a difference in group means,

- statistical tests of differences between matched treated and non-treated jobseekers' results of dependent variables.

In order to apply the matching algorithms the balancing property of the model was first tested and confirmed. The common support option was used to identify the range of probability that contains the observations with enough common features to be taken into consideration (Pirciog et al., 2015).

Table3: Estimation of the net effect of the Graduate practice

\begin{tabular}{cccc}
\hline Effect of the intervention & Group of sample & Mean & Net effect \\
\hline Average assessment base in & non-treated & 564 & -82 \\
$\boldsymbol{E}$ & Treated & 482 & \\
Placed on labour market in & non-treated & 11,11 & \multirow{2}{*}{ months } \\
mon & Treated & 9,12 & \\
\hline
\end{tabular}

Source: the author's work

This article focuses more on the use of logistic regression in the counterfactual evaluation, so we will only put the results of the evaluation briefly. In Table 3 the estimation of the net 
effect of the intervention is listed as a difference in means of treated and non-treated groups. The effect is quantified in the field of wage represented with assessment base and of placement of the jobseeker on the labor market.

The differences between treated and non-treated jobseekers groups were then tested using the non-parametric independent samples Mann-Whitney $U$ test. The result of testing is the same in all cases: the null hypothesis that there is no difference between the group means were rejected. That means the difference in wage and placement on labour market between the treated and non-treated jobseekers are significant and could be attributed to the intervention. This means that the presented net effect is confirmed. Treated jobseekers remained on average on labour market for about $17 \%$ of the entire impact period longer than the controls. This effect of Graduate practice is achieved mostly due to placement in full-time jobs.

In the context of the test results it is possible to note that treated individuals earned on average about $15 \%$ less money than control individuals.

\section{Conclusion}

Graduate practice is one of the mostly used interventions of ALMP treatments in Slovakia. Its main goal is to help unemployed young graduates to improve their status on the labour market due to obtaining the relevant professional skills and practical experiences that would be valuable and attractive for employers. Counterfactual evaluation by Propensity score matching method serves on estimation the probability of every jobseeker to participate in the intervention by using logistic regression model. Propensity score of every individual is then used to estimate the real net effect of the Graduate practice by matching treated and nontreated jobseekers with the same score. The net effect represents an answer for the fundamental counterfactual evaluation question: Does the Graduate practice affect employability and sustainability on the open labour market? Or, simply: what would have happened if the intervention had not existed?

As the evaluation showed, placement on the open labour market of young participants was sustained for a significantly longer time than non-participants of Graduate practice. We measured that the placement on the labour market during the impact period of 2 years after the intervention was for participants of the intervention up to half a year longer than of those eligible jobseekers that did not want to attend the Graduate practice. Mostly graduates were placed in full-time jobs; very rarely did they have interest in becoming self-employed, which was considered as another type of placement on the labour market. The statistical tests confirmed a significant positive treatment effect on participants' placement on the labour market due to the intervention.

\section{References}

[1] Asian Development Bank, Manila 2014. Techniques on Impact Evaluation: Propensity Score Matching. ADB-3ie-PIDS Conference on Impact Evaluation. [cit. 23-04-2017]. http://www.3ieimpact.org/media/filer_public/2014/09/16/17_techniques_on_impact_evalu ation_propensity_score_matching.pdf

[2] Bondonio, D. and Greenbaum, R. T. 2014. Revitalizing regional economies through enterprise support policies: an impact evaluation of multiple instruments. European urban and regional studies, vol. 21, iss. 1, pp. 79-103.

[3] Borik, V., Durica, M., Molnarova, M. and Svabova, L. 2015. The net effects of graduate work experience and the promotion of self-employment, Technical Report. Final Report of the Project of European Commission supported from the European Social Fund: 
VS/2014/0072 Pilot Counterfactual Impact Evaluation of Self-employment and Graduate Practice. [cit. 21-06-2015]. https://www.employment.gov.sk/files/slovensky/esf/opzasi/technical-evaluation-report_final5edit.pdf

[4] Durica, M. 2016. Counterfactual methods used for evaluation of active labor market policies in European Union. Proceedings of 16th international scientific conference Globalization and its socio-economic consequences 2016, Part I. Rajecke Teplice, Slovak Republic. pp. 399-407.

[5] European Commision, Directorate-General for Employment, Social Affairs and Inclusion. 2012. Design and commissioning of counterfactual impact evaluations: A Practical Guidance for ESF Managing Authorities. [cit. 11-06-2016] https://crie.jrc.ec.europa.eu/sites/default/files/documents/CIE_Guidance_EN.pdf

[6] Field, A. 2014. Discovering statistics using IBM SPSS (4th ed.). London: SAGE. ISBN 978-1-4462-4918-5.

[7] Holmlund, B. 2001. What are the effects of active labour market policy? An introduction. Swedish Economic Policy review, vol. 8, pp. 3-7.

[8] Khandker, S. R., Koolwal, G. B. and Samad H. A. 2010. Handbook on Impact Evaluation: Quantitative Methods and Practices. Washington D. C., The World Bank.

[9] Kral, P., Kanderova, M., Kascakova, A., Nedelova, G., Valencakova, V. 2009. Viacromerne statisticke metody so zameranim na riesenie problemov ekonomickej praxe. Banska Bystrica: Univerzita Mateja Bela. 175 p. ISBN 978-80-8083-840-9.

[10] Lindley, J., Mcintosh, S., Roberts, J., Murray C. C., Edlin, R. 2015. Policy evaluation via a statistical control: A non-parametric evaluation of the 'Want2Work' active labour market policy. Economic Modelling, vol. 51, pp. 635-645.

[11] Paz, S. L. 2014. The impacts of trade liberalization on informal labor markets: A theoretical and empirical evaluation of the Brazilian case. Journal of International Economics, vol. 92, pp. 330-348.

[12] Pirciog, S., Ciuca V., Popescu, M. E. 2015. The net impact of training measures from active labour market programs in Romania - subjective and objective evaluation. Procedia Economics and Finance, vol. 26, pp. 339-344.

[13] Pirog, D. 2015. A geography graduate's transition into the labour market in Poland: a quantitative and qualitative evaluation of the process. Bulletin of Geography. Socioeconomic Series, vol. 29, pp. 103-118.

[14] Potluka, O., Bruha, J. 2011. Use of counterfactual impact evaluation in management of public expenditure programmes. Proceedings of 5th International Days of Statistics and Economics. Prague, Czech Republic, pp. 502-512.

[15] Potluka, O., Bruha, J., Vozar, O., Spacek, M., Loun, J., Polakovic, R. 2012. First results of the counterfactual impact evaluation of ESF assistance in the Czech Republic. Proceedings of 6th International Days of Statistics and Economics. Prague, Czech Republic, pp. 954-962.

[16] Rodriguez-Planas, N., Benus, J. 2006. Evaluating Active Labor Market Programs in Romania. Discussion Paper Series IZA DP, vol. 2464, iss. November 2006.

[17] Stankovicova, I., Vojtkova, M. 2007. Viacrozmerne statisticke metody s aplikaciami. Bratislava: IURA Edition. 261 p. ISBN 978-80-8078-152-1. 
[18] Szitasiova, V. 2015. Does the support make a difference? Counterfactual impact evaluation of education subsidy in Slovakia. Proceedings of 5th Central European conference in regional science. Kosice, Slovakia, pp. 1040-1051. 